\title{
UPCOMING DENTIST: WRAP UP YOUR MARKETING SKILLS WITH THESE SECRET INGREDIENTS
}

\author{
HARIS RAFIQI ${ }^{1}$ \& SANA FAROOQ ${ }^{2}$ \\ ${ }^{1}$ B.Eng (Deakin University Australia) Hons, MBA (University of Nottingham)
}

${ }^{2}$ M.D.S Pediatric and Preventive Dentistry, Senior Resident Government Dental College and Hospital, Srinagar, Kashmir

\begin{abstract}
Marketing matters in dentistry more than ever in the present advanced era where everything is available on the digital platform and patients are already aware and educated about the various dental procedures so dentists as such should be well versed with proper marketing strategies to attract patients and interact to make the patient understand every step of the treatment they are undergoing.

KEYWORD: SERPs, Dental marketing, Digital
\end{abstract}

Received: May 15, 2021; Accepted: Jun 05, 2021; Published: Jul 24, 2021; Paper Id.: IJSMMRDDEC20212

\section{INTRODUCTION}

The digital realm is where most of the prospective patients of a dentist are found these days and having a digital presence, website, listing, social media channels help in the growth of the dentist. ${ }^{1}$

For the provision of best oral health care services, the marketing recognizes the demand and supply side as two essential elements where the demand side consists of patients demographics, financing of care, the need for dental care, the economic cost of treatment whereas the supply consists of dentist demographics, his dental clinic, the number of hours he invests in the treatment and the staff and the receptionists at the dental setup. ${ }^{2}$

The blogging about healthy oral habits and encouraging dental checkups on the website not only helps him /her to rank higher on a SERP (search engine result pages) but also helps to connect with the potential and existing patients.

Dental marketing also includes the type of video as an introductory video, provider profile video, patient testimonial or review video, dental treatment in procedure overviews, educational videos and FAQs and for these videos we need a combination of a tripod stand, stabilizers, microphone on a modern smartphone on which we can do the editing and we should be able to create user-generated content (USG) for the social media feeds.

Having a clear visual identity is important for creating a brand for the dental office /dental clinic which is a combination of logo, typeface, colours and words used to represent the dental office services and values. ${ }^{3}$ Dental marketing and advertising provide an in and out approach to build and expand the dental practice and reflect good results in terms of increase in patients turnout. ${ }^{4}$

Ethical and diligent use of Instagram for posting dental related topics may help in contributing greatly to the world of dentistry by serving as an educating platform and improving clinical outcomes for patients. ${ }^{5}$ 


\section{Steps to Improve Your Marketing Skills}

\section{A) Improve Your Web Presence}

Establishing a solid reputation on various social platform is the best way to win over people and having the right marketing strategy can change an uncomfortable experience into one in which the patient completely trusts the health care caregiver. ${ }^{6}$ It is necessary to secure the site with HTTPS.

\section{b) By using the Right Search Engine Result Pages (SERPs) with Relevant Keywords}

Many times, a dentist can explain very well between the two options he is providing for the treatment of particular teeth like crowns versus veneers where he can easily enumerate the right differences about teeth being treated so that the prospective patient will be able to gauge his expertise and build a trust thus making him more popular.

\section{c) Educate the Patients Related to Dental Hygiene and the Various Issues to be Addressed by Writing a Blog}

Posting simple and user centric presentations or graphics to educate the mass is related to the various oral hygiene needs can help in familiarising your dental clinic with the general masses. Educate the patients about the dental benefits they are deriving from the dental insurance and the benefits they are paying for but not using them so that they gain trust with you.

\section{d) Using Online Platforms}

The dentist can show his skills on Instagram and having a question-answer session and interactive session in the Instagram stories will help in educating and familiarizing the followers with the dental setup.

\section{e) Sharing the Before and after work}

To show the visual impact of your work can be a natural way to show your capabilities to the masses mostly in the field of Cosmetic dentistry, Pediatric dentistry and Orthodontics.

\section{f) Setting up Groups and Networks with the General Medical Practitioners}

General Medical groups may help in referring their patients and the local community to the particular dentist and thus help in networking of the dentist.

\section{g) Leveraging Social Proof on the public Platforms Like Facebook, Instagram, YouTube, Twitter, Bling, LinkedIn}

This will help the local community value your practice and there will be a sense of trust. It is mandatory to provide a website to locate the dentist and ask the patient to give online ratings.

\section{h) Create a Paid Advertisement on Sites Where Adult Spends at Least 50 Minutes Per Day: ${ }^{7}$}

Creating an advertisement by targeting a particular demographic area to narrow down the audience like a pediatric dentist needs to address the kid population while the people interested in fashion and beauty blogging will be the right candidates for a Cosmetic dentist In many countries advertisement of dental professionals has been made legal with certain guidelines and regulations. ${ }^{8}$

\section{i)Make Graphic Videos About the Dental Practice}

Instagram reels of your dental setup to attract patients and making funny and interactive videos with the patients colourful branding to reassure parents worried about their child visiting a dental clinic. For instance, a Pediatric dentist can post a 
colorful playful kid-friendly video with animated graphics to help in communication with the child as well as the parent thus addressing the holistic approach.

\section{j) Giving the Receptionist an Easy New Caller Sheet}

Make a foolproof way to collect all the must-have information about the patient like their demographics, their address, phone numbers, email addresses and how they were able to know about your dental clinic and thus it can be an easy tracking system to communicate with the patient.

\section{k) Assigning a Proper Tracking Number to each Marketing Channel}

\section{l) Use Google Map and Search to Localize Whose the Nearest and Greatest Competition in the Market}

According to research $84 \%$ of the 'near me' searches are carried out on mobile devices and $77 \%$ of the consumers/ patients go online to locate and look for the dentist when they search dental treatments which they require. Dentists compete with their colleagues for each patient as there is an ongoing shift to a patient-centric approach where patient satisfaction determines the achievement of quality offered to the patient. ${ }^{9}$

\section{m) Developing a USP (Unique Selling Proportion)}

By having a proper statement that why your dental setup is better than the rest like we make chairside crowns, accept dental insurance, are ranked number one dentist by the magazine or provide $24 / 7$ emergency care.

\section{n) Creating a Google My Business}

Account using Gmail where the name, address, operating hours business strategy, site link, service area, appointment and photos of the dental practice being provided are uploaded.

\section{o) Video Content}

which canS be used as a testimonial that how professional, experienced, reliable and trustworthy the dentist is while handling the dental cases.

\section{p) Create a Strong and Well Designed Site}

The patients' first interaction begins on the site and it tends to be the dentist's first impression so it needs to look professional, well organised, easily navigated which thoroughly educates and informs the visitor about the whole dental practice. ${ }^{10}$ On the site introduction of dental staff members, the dentist office environment and easier online scheduling should be done.

q) Use of Postcards and Mailed Offers: Sending of brochures to the high income neighborhoods where the residents are able to afford the cosmetic dentistry.

\section{r) Visiting Card}

\section{s) Arranging Dental Camps in Schools and Villages}

The major mistake a dentist can do while marketing is to emulate another dentist practice rather than focusing on what makes the practice so unique. 


\section{CONCLUSIONS}

Dental healthcare professionals need to be well aware to comprehend the need for advertising and showcasing whatever procedures they are going to do in their dental setup on a digital platform. The online advertisements and the use of social media for advertising and promoting the dental administration can be a boon because it helps in targeting the objective gathering.

\section{REFERENCES}

1. Alex Membrillo.10 dental marketing strategies you implement right now. Cardinal healthcare marketing

2. Hassan SA, Bhateja S, Arora G, Prathusha F.Marketing in dentistry. Journal of management research and analysis. $2020 ; 7$ (3): $98-100$

3. Marketing in dentistry: Opinion survey on promotion of the dental office. Revista De Cercetare Si Interventie Sociala.2018 ;63: $346-358$

4. Rulz RP. Dental marketing BMEG Approach (build, market, expand and group practice ). International Journal of dentistry and oral health. $2019 ; 5(3) ; 1-5$

5. Ooi HL, Kelleher MGD. Instagram dentistry.Prim Dent J.2021;10(1): 13-19

6. Suchi Sajja.How to win patients with social dental media marketing.

7. Joy Gendusa. The ultimate dental marketing plan: 23 steps to $147 \%$ more patients.dentistry IQ.

8. Shukla H, Chandhok S, Rojekar $N$ et al. Marketing in dentistry: a cross sectional study. Int gJ Health Sci Res.2019;9 (3 ):128 136

9. Dewi FD, Sudjana G, Oesman YM. Patient satisfaction analysis on service quality of dental health care based on empathy and responsiveness. Dental research journal. 2011;8:172

10. 11 effective dental patient marketing methods your practice should use. Receptive. 2018

11. Al-Somaiday, Humam Mahmoud, and Manar Eyad Al-Samaray. "MEASURING THE EXTENT OF PATIENTS'SATISFACTION WITH THE QUALITY OF SERVICES OFFERED BY DENTISTS IN IRAQ." International Journal of Business Management \& Research (IJBMR) 5.1 :49-60.

12. HEENAKAUSAR, D., and N. SHAIK MOHAMED. "DIMENSIONS OF PATIENT ATTITUDE TOWARDS DOCTOR AND MEDICAL CARE SERVICES." International Journal of Economics, Commerce and Research (IJECR) Special, Issue : 228236.

13. Rao, V., and R. Choudhury. "A study of the factors influencing customer satisfaction in medical tourism in India." International Journal of Business and General Management 6.5 : 7-22.

14. Bhattacharya, Mayuri Banerjee, S. C. Upaddhay, and Arvind Kurmar. "Socio Economic and Nutritional Status in "Agariyas": Salt Cultivators" Work as Contractual Manpower in Organized Salt Industries. "International Journal of Applied and Natural Sciences (IJANS) 7.6: 69-84. 